\title{
Short communication: Effects of prill size of a palmitic acid-enriched fat supplement on the yield of milk and milk components, and nutrient digestibility of dairy cows
}

\author{
J. de Souza, J. L. Garver, C. L. Preseault, and A. L. Lock ${ }^{1}$ \\ Department of Animal Science, Michigan State University, East Lansing 48824
}

\begin{abstract}
The objective of our experiment was to evaluate the effects of prill size of a palmitic acid-enriched fatty acid supplement (PA; 85\% C16:0) on feed intake, nutrient digestibility, and production responses of dairy cows. Twenty-four primiparous and multiparous Holstein cows were assigned based on parity and production level to replicated $4 \times 4$ Latin squares balanced for carryover effects with 21-d periods. Treatments were a control diet (no added PA), or $2.0 \%$ PA added as a small prill size (PA-SM; $284 \pm 12.4 \mu \mathrm{m})$, a medium prill size (PA-MD; $325 \pm 14.7 \mu \mathrm{m}$ ), or a large prill size (PA-LG; $600 \pm 17.4 \mu \mathrm{m})$ supplement. Overall, PA treatments increased milk fat content (4.25 vs. $3.99 \%)$, milk fat yield (1.48 vs. $1.39 \mathrm{~kg} / \mathrm{d}), 3.5 \%$ fat-corrected milk (39.2 vs. $37.7 \mathrm{~kg} / \mathrm{d}$ ), and improved feed efficiency (fat-corrected milk:dry matter intake; 1.51 vs. 1.42) compared with control. Compared with control, PA treatments did not affect dry matter intake, body weight, body condition score, or yields of milk, protein, and lactose. The PA treatments increased neutral detergent fiber digestibility (44.8 vs. $42.4 \%$ ) and reduced the digestibility of 16-carbon fatty acids (72.3 vs. $79.1 \%$ ) and total fatty acids (76.6 vs. $80.3 \%$ ). Compared with control, PA treatments reduced the contents of de novo synthesized milk fatty acids (23.0 vs. $25.8 \mathrm{~g} / 100 \mathrm{~g}$ of fatty acids) and preformed milk fatty acids (36.3 vs. $39.1 \mathrm{~g} / 100 \mathrm{~g}$ of fatty acids), but did not affect their yields. In contrast, PA treatments increased the content (40.8 vs. $35.1 \mathrm{~g} / 100 \mathrm{~g}$ of fatty acids) and yield (570 vs. $436 \mathrm{~g} / \mathrm{d}$ ) of 16-carbon milk fatty acids compared with control. The PA prill size had no effect on dry matter intake, yield of milk and milk components, or feed efficiency. However, PA-LG tended to increase milk fat content compared with PA-SM (4.28 vs. $4.22 \%$ ), and it
\end{abstract}

Received June 14, 2016.

Accepted September 1, 2016.

${ }^{1}$ Corresponding author: allock@msu.edu increased 16-carbon fatty acid digestibility compared with PA-MD (74.2 vs. $71.0 \%)$ and PA-SM (74.2 vs. $71.7 \%$ ). Additionally, PA-LG increased total fatty acid digestibility compared with PA-MD (78.1 vs. $75.6 \%$ ) and PA-SM (78.1 vs. 76.0\%). Results demonstrate that PA increased milk fat content and yield, and feed efficiency. Reducing prill size decreased fatty acid digestibility, but it had no effect on animal performance under the dietary conditions and prill sizes evaluated.

Key words: fat supplementation, milk fat, palmitic acid, prill size

\section{Short Communication}

Fat supplements are commonly used in dairy cow diets to meet energy requirements and increase the yields of milk and milk components (Rabiee et al., 2012). Supplementation with palmitic acid (C16:0) has been reported to increase milk yield, milk fat content and yield, and feed efficiency (Mosley et al., 2007; Piantoni et al., 2013). However, variation in response to palmitic acid has also been reported, with some studies reporting no effect on milk yield (Lock et al., 2013; Rico et al., 2014) and others reporting increases in milk yield (Mosley et al., 2007; Piantoni et al., 2013). Therefore, understanding potential factors (e.g., basal diet composition, characteristics of fat supplement) that may be associated with this variation may allow for more precise feeding recommendations.

The particle size of saturated fat supplements has been suggested as a factor that may affect fatty acid (FA) digestibility and production responses in dairy cows (Eastridge and Firkins, 1991). Eastridge and Firkins (2000) evaluated a tallow triglyceride supplement with different particle sizes but similar iodine values and FA profiles, and observed that reducing the particle size increased FA digestibility, milk fat yield, and FCM. Our recent meta-analysis indicated that the intestinal digestibility of palmitic acid was not reduced up to $500 \mathrm{~g} / \mathrm{d}$ duodenal flow (Boerman et al., 2015). In contrast, Piantoni et al. (2013) reported a reduction in 
16-carbon and total-tract FA digestibility when feeding a $99 \%$ palmitic acid-enriched supplement ( $2 \%$ of diet $\mathrm{DM})$, an effect that was potentially attributed to the physical characteristics and particle size of the supplement.

Based on the above-mentioned results, we hypothesized that dairy cow responses to palmitic acid supplementation may differ depending on the prill size of the supplement, with a smaller prill size supplement increasing FA digestibility. Therefore, the objective of our experiment was to evaluate the effects of prill size of a palmitic acid-enriched supplement on feed intake, nutrient digestibility, and production responses of dairy cows.

Experimental procedures were approved by the Animal Care and Use Committee of Michigan State University. Twenty-four (8 primiparous and 16 multiparous) mid-lactation Holstein cows at the Michigan State University Dairy Field Laboratory were used in replicated $4 \times 4$ Latin squares, balanced for carryover effects with 21-d periods. Cows were blocked and assigned to squares based on parity and preliminary $3.5 \%$ FCM. At the beginning of the trial, mean DIM, BW, and $3.5 \% \mathrm{FCM}$ (mean $\pm \mathrm{SD}$ ) were $120 \pm 44 \mathrm{~d}, 660 \pm$ $53 \mathrm{~kg}$, and $44.3 \pm 5.1 \mathrm{~kg} / \mathrm{d}$, respectively.

Treatments consisted of a control diet containing no supplemental fat (control), and a palmitic acidenriched supplement (PA, $85.1 \mathrm{~g} / 100 \mathrm{~g}$ of C16:0 FA) at $2.0 \%$ of diet DM fed as small (PA-SM), medium (PA-MD), or large (PA-LG) prill-sized supplement. The particle-size distribution of the fat supplements is presented in Supplementary Table S1 (https://doi. org/10.3168/jds.2016-11610). The mean particle sizes of the fat supplements were 284,324, and $600 \mu \mathrm{m}$ for PA-SM, PA-MD, and PA-LG, respectively. Although the average particle size was similar between PA-SM and PA-MD, PA-SM had a greater proportion of particles retained in the $150-\mu \mathrm{m}$ and $212-\mu \mathrm{m}$ sieves than PA-MD. In contrast, PA-LG had a greater proportion of particles retained in the $450-\mu \mathrm{m}$ and $600-\mu \mathrm{m}$ sieves.

Table 1. Ingredient and nutrient composition of treatment diets

\begin{tabular}{|c|c|c|c|c|}
\hline \multirow[b]{2}{*}{ Item } & \multicolumn{4}{|c|}{ Treatment $^{1}$} \\
\hline & $\mathrm{CON}$ & PA-SM & PA-MD & PA-LG \\
\hline \multicolumn{5}{|l|}{ Ingredient, $\%$ of $\mathrm{DM}$} \\
\hline Corn silage & 28.5 & 28.5 & 28.5 & 28.5 \\
\hline Alfalfa silage & 16.3 & 16.3 & 16.3 & 16.3 \\
\hline Wheat straw & 1.00 & 1.00 & 1.00 & 1.00 \\
\hline Ground corn & 23.5 & 23.5 & 23.5 & 23.5 \\
\hline Soybean meal $(48 \% \mathrm{CP})$ & 8.81 & 8.81 & 8.81 & 8.81 \\
\hline Whole cottonseed & 5.79 & 5.79 & 5.79 & 5.79 \\
\hline Soy hulls & 11.8 & 9.80 & 9.80 & 9.80 \\
\hline Amino acid supplement ${ }^{2}$ & 1.40 & 1.40 & 1.40 & 1.40 \\
\hline Palmitic acid-enriched supplement ${ }^{3}$ & - & 2.00 & 2.00 & 2.00 \\
\hline Vitamin and mineral mix & 1.80 & 1.80 & 1.80 & 1.80 \\
\hline Limestone & 0.51 & 0.51 & 0.51 & 0.51 \\
\hline Sodium bicarbonate & 0.59 & 0.59 & 0.59 & 0.59 \\
\hline \multicolumn{5}{|l|}{ Nutrient composition, \% of DM } \\
\hline $\mathrm{DM}^{5}$ & 49.2 & 49.2 & 49.2 & 49.2 \\
\hline NDF & 34.3 & 33.0 & 33.0 & 33.0 \\
\hline $\mathrm{CP}$ & 15.6 & 15.4 & 15.4 & 15.4 \\
\hline Starch & 25.9 & 25.9 & 25.9 & 25.9 \\
\hline Total fatty acids & 2.90 & 4.81 & 4.82 & 4.82 \\
\hline $\mathrm{C} 16: 0$ & 0.49 & 2.08 & 2.11 & 2.11 \\
\hline $\mathrm{C} 18: 0$ & 0.11 & 0.17 & 0.14 & 0.14 \\
\hline C18:1 cis-9 & 0.53 & 0.67 & 0.68 & 0.69 \\
\hline $\mathrm{C} 18: 2$ cis- 9, cis-12 & 1.51 & 1.54 & 1.54 & 1.55 \\
\hline $\mathrm{C} 18: 3$ cis- 9, cis- 12, cis -15 & 0.17 & 0.16 & 0.16 & 0.16 \\
\hline
\end{tabular}

${ }^{1} \mathrm{CON}$ (control diet, no addition of palmitic acid); PA-SM (small prill of palmitic acid); PA-MD (medium prill of palmitic acid); and PA-LG (large prill of palmitic acid).

${ }^{2}$ LysAAmet (Perdue AgriBusiness, Salisbury, MD).

${ }^{3} \mathrm{C} 16$ :0-enriched supplement (Wawasan Agrolipids, Johor, Malaysia). The supplement contained (g/100 g of fatty acid) 1.5 of C14:0, 85.1 of C16:0, 2.5 of C18:0, 7.9 of C18:1 cis-9, and 99.0 of total fatty acids.

${ }^{4}$ Vitamin and mineral mix contained $34.1 \%$ dry ground shelled corn, $25.6 \%$ white salt, $21.8 \%$ calcium carbonate, $9.1 \%$ Biofos (The Mosaic Co., Plymouth, MN), $3.9 \%$ magnesium oxide, $2 \%$ soybean oil, and $<1 \%$ of each of the following: manganese sulfate, zinc sulfate, ferrous sulfate, copper sulfate, iodine, cobalt carbonate, vitamin $\mathrm{E}$, vitamin $\mathrm{A}$, vitamin $\mathrm{D}$, and selenium.

${ }^{5}$ Percent of as-fed diet. 
The PA supplements replaced soy hulls in the diets, which were formulated to meet the requirements of the average cow in the group (NRC, 2001; Table 1).

All cows were housed in the same tiestall (assigned randomly) throughout the experiment and were milked twice daily $(0500$ and $1600 \mathrm{~h})$. Access to feed was blocked from 1000 to $1200 \mathrm{~h}$ for collection of orts and offering of new feed. Cows were fed at $115 \%$ of expected intake at $1200 \mathrm{~h}$ daily. Water was available ad libitum in each stall.

Samples and data for production and digestibility variables were collected during the last $5 \mathrm{~d}$ of each treatment period (d 17 to 21). Feed ingredients and orts were collected daily, composited by period, and analyzed for DM, NDF, CP, starch and FA contents as described by Boerman and Lock (2014). Fecal samples (500 g) were collected every $15 \mathrm{~h}$, resulting in 8 samples per cow per period, and nutrient digestibility was calculated using indigestible NDF as an internal marker, as previously described (Piantoni et al., 2013). Supplements were composited by period, and particle size distribution was determined according to AOAC (1990; method 965.22). Briefly, duplicate samples of each supplement $(100 \mathrm{~g})$ were placed on the top screen $(3,350$ $\mu \mathrm{m}$ ) of a testing sieve (Ro-Tap Sieve Shakers; W.S. Tyler, Mentor, $\mathrm{OH}$ ) and agitated at $150 \mathrm{taps} / \mathrm{min}$ for 10 min. Sieves with 3,350-, 2,360-, 1,700-, 1,180-, 850-, 600-, 425-, 300-, 212-, 150-, 106-, 75-, 53-, and 37- $\mu \mathrm{m}$ pores were used. The amount of sample held on each screen was collected, weighed, and used for particle-size calculations. Individual milk samples were analyzed for fat, true protein, and lactose by mid-infrared spectroscopy (AOAC, 1990; method 972.160), and for FA using GLC (Lock et al., 2013). Yields of 3.5\% FCM,
ECM, and milk components were calculated using milk yield and component concentrations for each milking, summed for a daily total, and averaged for each collection period. Body weight was recorded on the last $2 \mathrm{~d}$ of each period. Three trained investigators determined BCS on the last day of each treatment period using a 5 -point scale with 0.25 -point increments according to Wildman et al. (1982).

Data were analyzed using the MIXED procedure in SAS (version 9.2; SAS Institute Inc., Cary, NC). The statistical model included the fixed effects of square, treatment, and period, as well as 2-way interactions between these factors, and the random effect of cow nested within square. When interactions were not significant $(P>0.20)$, they were removed from the model. Three preplanned contrasts were used to evaluate (1) the effect of PA treatments [control vs. PA; (PA-SM + PA-MD + PA-LG)/3]; (2) the effect of large prill size compared with small prill size (PA-LG vs. PA-SM); and (3) the effect of large prill size compared with medium prill size (PA-LG vs. PA-MD). Contrasts were declared significant at $P \leq 0.05$ and trends at $0.05<P \leq 0.10$.

The PA treatments did not affect DMI compared with control $(P=0.16$; Table 2$)$. These results agree with most studies feeding highly enriched $(\geq 85 \%)$ sources of palmitic acid, in which DMI is typically not decreased when palmitic acid is fed up to $2 \%$ of diet DM (Piantoni et al., 2013; de Souza et al., 2016). In contrast, we observed that PA treatments reduced NDF intake compared with control $(P=0.01)$, mainly a result of the lower NDF content in the PA diets due to the removal of soy hulls in the PA treatments. As expected, PA treatments increased intake of 16-carbon FA and total FA compared with control $(P<0.01)$. We

Table 2. Nutrient intake and total-tract digestibility of cows fed treatment diets $(\mathrm{n}=24)$

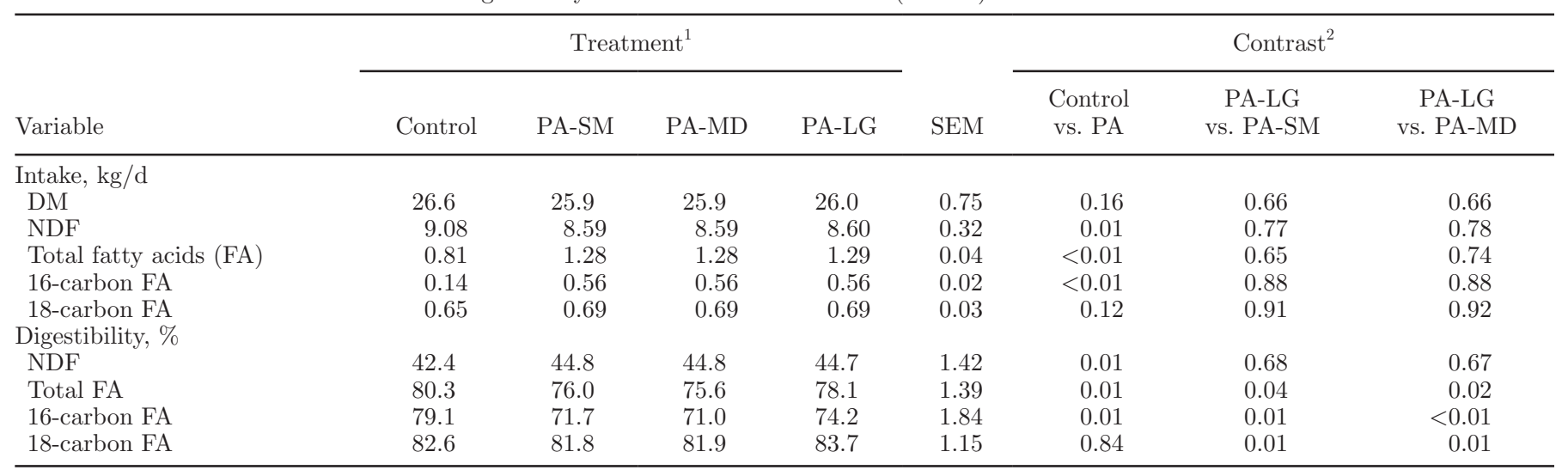

${ }^{1}$ Treatments were either control ( $2 \%$ of diet DM as added soy hulls) or palmitic acid-enriched supplements (2\% diet DM) fed as small (PA-SM), medium (PA-MD), or large (PA-LG) prill size.

${ }^{2} P$-values associated with contrasts: $(1)$ the effect of PA treatment [control vs. PA; (PA-SM + PA-MD + PA-LG)/3]; (2) the effect of large prill size compared with small prill size (PA-LG vs. PA-SM); and (3) the effect of large prill size compared with medium prill size (PA-LG vs. PA-MD). 
observed no effect of prill size for DMI and intake of nutrients (all $P>0.10$ ).

The PA treatments increased NDF digestibility compared with control (44.8 vs. $42.4 \% ; P=0.01$ ). These results are in agreement with previous studies feeding palmitic acid (Warntjes et al., 2008; Piantoni et al., 2013). The increase in NDF digestibility may be associated with an increase in retention time driven by an increase in cholecystokinin secretion (Piantoni et al., 2013) and partially due to the lower NDF content of the PA treatments. Compared with control, PA treatments reduced the digestibility of 16-carbon FA (72.3 vs. $79.1 \% ; P=0.01)$ and total $\mathrm{FA}(76.6$ vs. $80.3 \%$; $P=0.01$ ). Although Rico et al. (2014) reported that feeding a highly enriched palmitic acid supplement $(2 \%$ diet DM; 85\% C16:0) had positive effects on 16-carbon and total FA digestibility, Piantoni et al. (2013) observed a reduction in FA digestibility when feeding a palmitic acid-enriched supplement (2\% of diet DM; 99\% C16:0). In a recent meta-analysis, Boerman et al. (2015) observed no reduction in FA digestibility when the duodenal flow of palmitic acid increased up to 500 $\mathrm{g} / \mathrm{d}$, whereas increasing the duodenal flow of stearic acid up to $500 \mathrm{~g} / \mathrm{d}$ reduced FA digestibility. While total flow of FA at the duodenum affects FA digestibility (Boerman et al., 2015), these findings suggest that the profile of FA entering the duodenum is a critical factor affecting FA digestibility. In our study, although the intake of 16-carbon FA was slightly over $500 \mathrm{~g} / \mathrm{d}$ for the PA treatments and PA treatments reduced FA digestibility, the reduction we observed was much less than that reported by Piantoni et al. (2013). Reasons for these differences might include the greater prill size $(890 \pm 140 \mu \mathrm{m})$ and content of $\mathrm{C} 16: 0$ (99\% C16:0) in Piantoni et al. (2013) compared with our current study. Therefore, different responses in FA digestibility might occur with supplements that have a larger prill size than those evaluated in our study. The exact mechanisms for the reduction in FA digestibility are unknown, but potential causes include competition for absorption sites, limits in emulsification, or both (Drackley, 2000).

Compared with PA-MD, PA-LG increased the digestibility of 16-carbon $(P<0.01)$, 18-carbon $(P=$ $0.01)$, and total $(P=0.02)$ FA. In addition, compared with PA-SM, PA-LG increased 16-carbon $(P=0.01)$, 18-carbon $(P=0.01)$, and total $(P=0.02)$ FA digestibility. Eastridge and Firkins (1991) observed that the total FA digestibility of flaked, partially hydrogenated tallow triglycerides (mean particle size 1,809 $\mu \mathrm{m}$ ) fed to dairy cows was only $38 \%$ and suggested that this might be increased by reducing the particle size of the fat supplement. Eastridge and Firkins (2000) evaluated a tallow triglyceride supplement fed as prills (mean particle size $600 \mu \mathrm{m}$ ) or flakes (mean particle size 1,180 $\mu \mathrm{m})$ and observed lower FA digestibility for the flaked supplement, an effect that was mainly attributed to particle size, because both fat supplements had similar FA profiles and iodine values. In our study, reducing prill size decreased FA digestibility, contradicting our initial hypothesis. Reducing prill size may increase the passage rate of FA from the rumen to the intestine. A greater flow of FA to the intestine in a shorter time may exceed the absorptive capacity of the intestine, reducing FA digestibility (Eastridge and Firkins, 2000; Boerman et al., 2015). Moreover, in our study, the prill sizes evaluated were smaller than those in the aforementioned studies, which might explain, at least in part, the differences in results.

Another possible factor affecting FA digestibility is the difference between the FA profiles of the supplements being evaluated. In particular, the supplements used in the present study contained mainly C16:0 $(\sim 85 \%)$, whereas supplements used in the abovementioned studies contained a mixture of C16:0 and C18:0 ( 40\% C16:0 + 40\% C18:0). Supporting this concept, Firkins and Eastridge (1994) observed that FA digestibility decreased as the proportion of C18:0 to C16:0 was increased in supplements of partially hydrogenated fat. Chamberlain and dePeters (2016) recently observed similar results when the proportion of C18:0 to C16:0 in free FA supplements was increased. These results are supported by our meta-regression findings, which indicated that increasing C18:0 flow through the duodenum negatively affects the digestibility of several FA (Boerman et al., 2015). This may suggest that fat supplements containing a greater proportion of C18:0 than C16:0 would have different responses when prill size is altered. This hypothesis needs to be further evaluated.

Overall, PA treatments did not affect milk yield ( $P$ $=0.98$; Table 3 ), increased $3.5 \%$ FCM (39.2 vs. 37.7 $\mathrm{kg} / \mathrm{d} ; P=0.04)$, and tended to increase ECM $(38.9$ vs. $37.9 \mathrm{~kg} / \mathrm{d} ; P=0.10)$ compared with control. We observed no effect of prill size on milk yield, $3.5 \% \mathrm{FCM}$, or ECM (all $P>0.10$ ). Although studies with palmitic acid-enriched supplements present some conflicting results regarding milk yield, most studies have shown that palmitic acid-enriched supplements increase 3.5\% FCM and ECM (Lock et al., 2013; de Souza et al., 2016).

Compared with control, the PA treatments increased milk fat content (4.25 vs. $3.99 \% ; P<0.01)$ and milk fat yield (1.48 vs. $1.39 \mathrm{~kg} / \mathrm{d} ; P<0.01)$. The increase in milk fat was due to the increase in yield of 16-carbon FA [derived from both de novo synthesis and extraction from plasma $(P<0.01)]$ without affecting the yield of de novo $(<16$-carbon FA; $P=0.18)$ or preformed FA $(>16$-carbon FA; $P=0.98)$. These results are in 
agreement with previous studies feeding palmitic acidenriched supplements (Lock et al., 2013; Piantoni et al., 2013). As a result of PA treatments increasing the content of 16-carbon FA in milk fat, the content of de novo FA $(<16$-carbon FA) was reduced compared with control $(P<0.01)$. Specifically, the contents of C6:0, C8:0, C10:0, C12:0, C14:0, and cis-9 C14:1 were reduced $(P<0.01$; Supplementary Table S2; https://doi. org/10.3168/jds.2016-11610). In contrast, for de novo FA yields, PA treatments reduced the yield of only C8:0 $(P=0.01)$ and C14:0 $(P=0.09)$ (Supplementary Table S3; https://doi.org/10.3168/jds.2016-11610). In addition, PA treatments increased the yield of C4:0 and C18:1 cis-9 $(P<0.01)$ compared with control, which likely occurs as part of the mechanism to maintain milk fluidity as uptake of C16:0 from plasma and its incorporation into milk fat increases (Jensen, 2002). Although PA-LG tended to increase milk fat content compared with PA-SM (4.28 vs. $4.22 \%$; $P=0.09$ ), we observed no effect on milk fat yield or yield of FA by source between these 2 treatments (all $P>0.25$ ).
Although PA treatments reduced milk protein content $(P=0.01)$, milk protein yield was not affected $(P$ $=0.47)$ compared with control. This reduction in milk protein content without affecting milk protein yield was consistently observed when responses to several sources of supplemental fat were reviewed (Rabiee et al., 2012). We observed no differences among treatments for yield and content of lactose in milk (all $P>0.10$ ). Overall, the PA treatments increased feed efficiency (FCM/ DMI) compared with control (1.51 vs. $1.42 ; P<0.01$ ), consistent with previous studies that fed palmitic acidenriched supplements (Piantoni et al., 2013; de Souza et al., 2016), because of the increase in 3.5\% FCM without affecting DMI. We observed no differences among treatments for BW or BCS (all $P>0.10$ ).

Our results demonstrate that supplementation with palmitic acid increases NDF digestibility, milk fat content and yield, and feed efficiency. Reducing prill size decreased FA digestibility, but this had no effect on animal performance under the current dietary conditions and prill sizes evaluated.

Table 3. Milk yield, milk composition, milk fatty acid (FA) concentration and yield, BW, and BCS of cows fed treatment diets $(\mathrm{n}=24)$

\begin{tabular}{|c|c|c|c|c|c|c|c|c|}
\hline \multirow[b]{2}{*}{ Variable } & \multicolumn{4}{|c|}{ Treatment $^{1}$} & \multirow[b]{2}{*}{ SEM } & \multicolumn{3}{|c|}{ Contrast $^{2}$} \\
\hline & Control & PA-SM & PA-MD & PA-LG & & $\begin{array}{l}\text { Control } \\
\text { vs. PA }\end{array}$ & $\begin{array}{c}\text { PA-LG } \\
\text { vs. PA-SM }\end{array}$ & $\begin{array}{c}\text { PA-LG } \\
\text { vs. PA-MD }\end{array}$ \\
\hline \multicolumn{9}{|l|}{ Milk yield, $\mathrm{kg} / \mathrm{d}$} \\
\hline Milk & 35.0 & 35.1 & 35.1 & 34.8 & 2.01 & 0.98 & 0.69 & 0.69 \\
\hline $3.5 \% \mathrm{FCM}^{3}$ & 37.7 & 39.4 & 39.2 & 39.0 & 1.67 & 0.04 & 0.72 & 0.87 \\
\hline $\mathrm{ECM}^{4}$ & 37.9 & 39.1 & 39.0 & 38.7 & 1.84 & 0.10 & 0.65 & 0.85 \\
\hline Fat, \% & 3.99 & 4.22 & 4.25 & 4.28 & 0.11 & $<0.01$ & 0.09 & 0.25 \\
\hline Protein, kg/d & 1.18 & 1.15 & 1.17 & 1.17 & 0.06 & 0.47 & 0.47 & 0.99 \\
\hline Protein, \% & 3.38 & 3.33 & 3.34 & 3.34 & 0.08 & 0.01 & 0.86 & 0.98 \\
\hline Lactose, $\mathrm{kg} / \mathrm{d}$ & 1.65 & 1.62 & 1.63 & 1.63 & 0.09 & 0.41 & 0.69 & 0.99 \\
\hline Lactose, \% & 4.72 & 4.62 & 4.64 & 4.64 & 0.08 & 0.40 & 0.65 & 0.98 \\
\hline \multicolumn{9}{|c|}{ FA concentration,$^{5} \mathrm{~g} / 100 \mathrm{~g}$ of FA } \\
\hline De novo & 25.8 & 23.1 & 23.0 & 22.9 & 0.36 & $<0.01$ & 0.07 & 0.26 \\
\hline Preformed & 408 & 406 & 405 & 412 & 15.9 & 0.98 & 0.75 & 0.67 \\
\hline FCM/DMI & 1.42 & 1.52 & 1.51 & 1.50 & 0.08 & $<0.01$ & 0.22 & 0.39 \\
\hline $\mathrm{BW}, \mathrm{kg}$ & 697 & 690 & 691 & 696 & 22.5 & 0.25 & 0.55 & 0.48 \\
\hline BCS & 3.31 & 3.29 & 3.27 & 3.28 & 0.12 & 0.21 & 0.69 & 0.51 \\
\hline
\end{tabular}

${ }^{1}$ Treatments were either control (2\% of diet DM as added soy hulls) or palmitic acid-enriched supplements (2\% diet DM) fed as small (PA-SM), medium (PA-MD), or large (PA-LG) prill size.

${ }^{2} P$-values associated with contrasts: $(1)$ the effect of PA treatments [control vs. PA; (PA-SM + PA-MD + PA-LG)/3]; (2) the effect of large prill size compared with small prill size (PA-LG vs. PA-SM); and (3) the effect of large prill size compared with medium prill size (PA-LG vs. PA-MD).

${ }^{3} 3.5 \% \mathrm{FCM}=[(0.4324 \times \mathrm{kg}$ of milk $)+(16.216 \times \mathrm{kg}$ of milk fat $)]$.

${ }^{4} \mathrm{ECM}=[(0.327 \times \mathrm{kg}$ of milk $)+(12.95 \times \mathrm{kg}$ of milk fat $)+(7.20 \times \mathrm{kg}$ of milk protein $)]$.

${ }^{5}$ De novo fatty acids originate from mammary de novo synthesis $(<16$ carbons), preformed fatty acids originate from extraction from plasma (>16 carbons), and mixed fatty acids originate from both sources (C16:0 plus cis-9 C16:1). Concentrations and yields of individual fatty acids are reported in Supplementary Tables S2 and S3 (http://dx.doi.org/10.3168/jds.2016-11610), respectively. 


\section{ACKNOWLEDGMENTS}

We acknowledge Perdue AgriBusiness (Salisbury, MD), Wawasan Agrolipids (Johor, Malaysia), Energy Feeds International (San Leandro, CA), and Michigan State University AgBioResearch for financial support of this research, and Wawasan Agrolipids (Johor, Malaysia) for the donation of the C16:0-enriched supplements. We also thank J. P. Boerman, J. E. Rico, Y. Sun, K. E. DeLand, and L. C. Nagengast (all in the Department of Animal Science, Michigan State University), and the staff of the Michigan State University Dairy Cattle Field Laboratory for their assistance in this experiment. Jonas de Souza was supported by a $\mathrm{PhD}$ fellowship from Coordenação de Aperfoiçamento de Pessoal de Nivel Superior (CAPES) from the Brazilian Ministry of Education (Brasilia, DF, Brazil).

\section{REFERENCES}

AOAC. 1990. Official Methods of Analysis. 15th ed. AOAC, Arlington, VA.

Boerman, J. P., J. L. Firkins, N. R. St-Pierre, and A. L. Lock. 2015. Intestinal digestibility of long-chain fatty acids in lactating dairy cows: A meta-analysis and meta regression. J. Dairy Sci. 98:88898903.

Boerman, J. P., and A. L. Lock. 2014. Effect of unsaturated fatty acids and triglycerides from soybeans on milk fat synthesis and biohydrogenation intermediates in dairy cattle. J. Dairy Sci. 97:7031-7042.

Chamberlain, M. B., and E. J. dePeters. 2016. Impacts of feeding lipids supplements high in palmitic acid or stearic acid on performance of lactating dairy cows. J. Appl. Anim. Res. http://dx.doi. org/10.1080/09712119.2015.1124327. In press.

de Souza, J., C. L. Preseault, and A. L. Lock. 2016. Short communication: Lactational responses to palmitic acid supplementation when replacing soyhulls or dry ground corn. J. Dairy Sci. 99:1945-1950.
Drackley, J. K. 2000. Lipid metabolism. Pages 97-119 in Farm Animal Metabolism and Nutrition. J. P. F. D'Mello, ed. CABI Publishing, New York, NY.

Eastridge, M. L., and J. L. Firkins. 1991. Feeding hydrogenated fatty acids and triglycerides to lactating dairy cows. J. Dairy Sci. 74:2610-2616.

Eastridge, M. L., and J. L. Firkins. 2000. Feeding tallow triglycerides of different saturation and particle size to lactating dairy cows. Anim. Feed Sci. Technol. 83:249-259.

Firkins, J. L., and M. L. Eastridge. 1994. Assessment of the effects of iodine value on fatty acid digestibility, feed intake, and milk production. J. Dairy Sci. 77:2357-2366.

Jensen, R. G. 2002. The composition of bovine milk lipids: January 1995 to December 2000. J. Dairy Sci. 85:295-350.

Lock, A. L., C. L. Preseault, J. E. Rico, K. E. DeLand, and M. S. Allen. 2013. Feeding a C16:0-enriched fat supplement increased the yield of milk fat and improved conversion of feed to milk. J. Dairy Sci. 96:6650-6659.

Mosley, S. A., E. E. Mosley, B. Hatch, J. I. Szasz, and A. Corato. 2007. Effect of varying levels of fatty acids from palm oil on feed intake and milk production in Holstein cows. J. Dairy Sci. 90:987-993.

NRC. 2001. Nutritional Requirements of Dairy Cattle. 7th rev. ed. Natl. Acad. Sci., Washington, DC.

Piantoni, P., A. L. Lock, and M. S. Allen. 2013. Palmitic acid increased yields of milk and milk fat and nutrient digestibility across production level of lactating cows. J. Dairy Sci. 96:7143-7154.

Rabiee, A. R., K. Breinhild, W. Scott, H. M. Golder, E. Block, and I. J. Lean. 2012. Effect of fat additions to diets of dairy cattle on milk production and components: a meta-analysis and metaregression. J. Dairy Sci. 95:3225-3247.

Rico, D. E., Y. Ying, and K. J. Harvatine. 2014. Effect of a highpalmitic acid fat supplement on milk production and apparent total-tract digestibility in high- and low-milk yield dairy cows. J. Dairy Sci. 97:3739-3751.

Warntjes, J. L., P. H. Robinson, E. Galo, and E. J. DePeters. 2008. Effects of feeding supplemental palmitic acid (C16:0) on performance and milk fatty acid profile of lactating dairy cows under summer heat. Anim. Feed Sci. Technol. 140:241-257.

Wildman, E. E., G. M. Jones, P. E. Wagner, and R. L. Bowman. 1982. A dairy cow body condition scoring system and its relationship to selected production characteristics. J. Dairy Sci. 65:495-501. 